\title{
Vibration harvesting integrated into vehicle suspension and bodywork
}

\author{
Souad Touairi, Mustapha Mabrouki \\ Industrial Engineering Laboratory (LGI), Faculty of Sciences and Techniques, Sultan Moulay Slimane \\ University (USMS), Beni Mellal, Morocco
}

\begin{tabular}{l}
\hline \hline Article Info \\
\hline Article history: \\
Received Feb 4, 2021 \\
Revised Jun 2, 2021 \\
Accepted Jun 11, 2021 \\
\hline
\end{tabular}

\section{Keywords:}

Electric power

Energy harvesting

Piezoelectric

Suspension system

Vibration energy

\begin{abstract}
This work proposes a new piezoelectric transducer system with four freedoms of movement modelled and evaluated by mechatronic techniques. The proposed modelling techniques (finite element and bond graph) were performed in a 20-Sim framework attached to the ANSYS software. The established harvester system has the ability to increase the driver's comfort when travelling on several types of road surfaces. The piezoelectric harvester is designed to investigate and provide the health requirement and ride comfort of the vehicle's drives on random road surfaces. The simulation results affirm that the improved piezoelectric transducer arrangement is more productive for various aspects. The power recovery is significantly enhanced as well as the driving comfort on the three road categories. Finally, the harvestable power amount is highlighted and is graphically discussed for several specific applications.
\end{abstract}

This is an open access article under the CC BY-SA license.

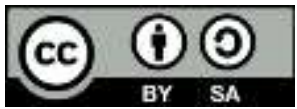

\section{Corresponding Author:}

Souad Touairi

Department of Physics, Industrial Engineering Laboratory

Faculty of Sciences and Techniques

Sultan Moulay Slimane University

Campus Mghila, BP 523, 23000 Beni Mellal, Morocco

Email: touairisouad@gmail.com

\section{INTRODUCTION}

Throughout the last decade, the adoption of autonomous electric vehicle, handheld wireless communications systems, smart instruments, and intelligent cities has been growing steadily. Those latter affect the demand for electrical energy (EE) which has also been increasing. This technological expansion has placed several constraints on electric power production by a proper and continuous source of electrical power. However, the power sources become a barrier because the quantity of energy consumed by the autonomous electric vehicle (AEV) is elevated due to the prolonged driving distances [1], [2]. In this respect, a novel piezoelectric transducer system has been announced to progress the recovery of vibrational energy and offer new efficiencies and implement new technologies [3], [4]. While vibrational energy scavenger (VES) utilizing the piezoelectric substance has previously been discussed in great scientific research database, many investigators have been focused on piezoelectric cantilever [5]. The main purpose is that the harvester's beams ensure a large electrical power amount for supplying several industries devices as; automotive area, sophisticated wireless radars and smart instruments [6], [7]. Furthermore, the VES schemes produce and store power close to loads and consumption needs [8]. This technique collects the ambient vibration energy of the weak suspension distortion and converts it into power supply [9]. The common performance of the piezoelectric package oscillates naturally in response to the normal superficial plane oscillation of the transducer's beams [10], these vibrations are noticed in the strain of unchanging surface 
material [11], [12]. The manoeuvre is essential to decrease the impact of vibration and preserve drivers by wasting this vibrational energy in dissipating heat [13]. Moreover, the whole suspension of the seat operates as a vibration isolator to remove the perturbation from high roughness of the road profile. The efforts of the researchers were implemented to enhance the transducer efficiency. The authors in [14] applied a transducer cantilever into wheel's tires to distributed power in the vehicles and synchronizing the storage of vibrational energy in the charging batteries. As a result, there has been growing progress in transducer engineering as a most powerful tool for the development of a more efficient system. Nevertheless, a past study has performed an extended and comprehensive analysis of the application of piezoelectric substance to collect vibration, namely energy scavenging from fuel generators in a nuclear energy factory [15]. In the very same situation, the scientific in [16], [17] have been reviewing these interesting areas and offering some solutions for modelling. In addition, piezoelectric energy recovery by vibration (PVEH) circuit and stocking detachment are widely discussed in the literature [18]. On the other side, there are many popular techniques that have been applied and realized to collect various vibration energies carry out on the vehicle body. This external excitation can change the vehicle's engine behaviour or the car's antilock brakes device (ABD) [19]. The authors of [20], [21] have been proposed an applicable strategy to collect high bandwidth of vibrations energy through the use of transducer attached to the suspension system. Nevertheless, this approach does not preserve conduction safety for the conductor due to the changed suspension properties. After reviewing the pertinent literature, the authors have struggled to solve two critical technical problems: Prototyped a transducer that needs process with low oscillation energy and appropriate shape factor for the suspension.

This article proposed a novel methodology for transducer modelling that provides an excellent overview and expands the power amount. The vibration harvesting system (VHS) device established in this paper ensures high performance for electric vehicle (EV) suspension with regard to a unified regenerative approach. Particularly the bond graph (BG) approach is applied to the whole harvester system (mechanical suspension components and piezoelectric transducer). In addition, the perpendicular, transversal and bilateral forces of the vehicle's suspension characteristics are evaluated. This approach takes into account the geometrical and non-linearities associated with the suspension system, including the piezoelectric hysteresis behaviour as well as the critical tire parameters. In addition, the appropriate matrix of mass, damping and stiffness states is calculated taking into account the dynamics of the EV. In additional, the hysteresis property of the piezoelectric actuator has been verified by employing an impulse wavelength modulation (PWM) with various operational cycles into MATLABISUMILINK frame. The model controlled dynamic damping parameters and input values were recognised trough the test results. The numerical values of the simulation demonstrate better vibration isolation. The system is established for the maximum/minimum damping and with a conventional reformative suspension. The system's recoverable power RMS is $386 \mathrm{~mW}$ though the consumption of the PWM automobile switch indicator is $122 \mathrm{~mW}$. Therefore, this damping factor of the suspension ensure comfortable ride through minimal power charge. Furthermore, the simulation affirm that the transducer attached in the path of thickness has around 35\% minor natural frequency and 10\% advanced output voltage $(10 \mathrm{~V})$ that the narrow-width transducer. Finally, this paper provides evidence that the piezoelectric beam can be employed in a vast array of applications, with equivalent mass and elevated output resistance, respectively. These values demonstrate that the improved instrument decrease strongly the influence among wheels and roads even preserving the operative vibration energy recovery capacity in electric energy (EE) from $50 \mathrm{~mW}$ to $7.4 \mathrm{~W}$.

\section{MECHATRONICS MODELLING METHODOLOGY}

Many advanced transducer systems in VHS are proposed and analysed but they didn't consider a standard connection model [22]. In this section, a mechanical shear harvesting system for the VHS technology with an unlimited number of input constraints and a maximum of output forces has been established. The dynamic behaviour of this transducer system is a function of the state of vertical and bounded horizontal forces (1). The piezoelectric hysteresis is modelled, and only the vertical movement, pitch rotation and roll movements of the vehicle were taken into account [23]. In addition, the piezoelectric beam attached to the conductor's seat suspension is exhibited to perturbation. This latter is a complicated dynamic function of movement for this type of complex mechanical component [24]. Moreover, the vehicle handling equation has been extracted excluding the transducer dynamics influence that adopted the produced force of the vertical movement of the system [25]. Furthermore, the exhibiting BG calculated the movement equations of conductor's seat suspension. These latter are composed of the passenger's suspension, conductor's mass and the roues suspension. The proposed BG composed of mass value, spring factor, and damper parameter's matrices for the piezoelectric harvester typical system. 


\subsection{Piezoelectric transducer mounted between the seat and the tyre suspension}

The most common piezoelectric material used in PVEH is PZTK-4 with D33 characteristics. The proposed system used zirconium lead ate that undergoes a structural stage transition when its infection drops to the Curie temperature [26], [27]. However, to determine its physical appearance for power flow, an electrified piezoelectric transducer unit has been modelled by the BG inverse Figure 1. This wave source is a sinusoidal source direct to the capacitor $\mathrm{C}_{\mathrm{pz}}$ of its middle conductor by the characteristics of the suspension (spring, mass and damper element) [26]. This concept discussed and established in a more detailed description in the next section. The magnitude input of excitation voltage $V_{p z}$ changes with the level of piezoelectric mechanical polarity that assumed to be continuous regardless of the external input load. According to this proposed model, the dynamic state equations of motion are presented as follows:

$$
\begin{aligned}
& M_{s m} Z^{\prime \prime}{ }_{2}(t)=M_{s m}\left(Z^{\prime \prime}{ }_{2}(t)-Z^{\prime \prime}{ }_{1}(t)\right)+C_{P Z T}\left(Z_{2}^{\prime}(t)-Z_{1}^{\prime}(t)\right)+K_{s p r}\left(Z_{2}(t)-Z_{1}(t)\right) \\
& +F_{\text {road }}\left(Z_{P Z T}(t)\right)
\end{aligned}
$$

where, $\mathrm{M}_{\mathrm{sm}}$ is the sprung mass $(\mathrm{kg}), \mathrm{K}_{\mathrm{spr}}$ is the suspension stiffness $(\mathrm{N} / \mathrm{m}), \mathrm{C}_{\mathrm{PZT}}$ is the suspension damping $(\mathrm{Ns} / \mathrm{m}), \mathrm{F}_{\text {road }}$ is the total vibration force $(\mathrm{N}), \mathrm{Z}_{1}$ unsprang mass motion $(\mathrm{m}), \mathrm{Z}^{\prime}{ }_{1}$ unsprang mass translation speed $(\mathrm{m} / \mathrm{s}), Z_{2}$ sprung mass motion $(\mathrm{m}), Z_{2}{ }_{2}$ sprung mass translation speed $(\mathrm{m} / \mathrm{s})$, Z $Z_{\mathrm{PZT}}$ motion of the piezoelectric beams according to the $\mathrm{D}_{33}(\mathrm{~m})$ and $Z^{\prime}{ }_{\text {PZT }}$ translation speed $(\mathrm{m} / \mathrm{s})$.

According to the IEEE standard factors, the link among the externally practical force employed on the PEA. The output movement is direct and proves the precise attachment optimal. This disruptive force produces a permanent shear deformation in the PZT material patches and as a result a mechanical movement on the sides of the PZT-7K surface in the course of polarization, calculated through the formula as follows:

$$
D_{33}=d_{33} \tau_{31}+\varepsilon_{11} E_{1}
$$

Including, the superficial potential-thickness movement $\mathrm{D}_{33}$ on the aspects of the PZT-7K areas; the PZT stress factor $\mathrm{d}_{33}$; the shave tension $\tau_{31}$ working normal to the track of the PZT propelling; the dielectric continual value $\varepsilon_{11}$ and the electrical ground $\mathrm{E}_{1}$ in the 1-path inside the PZT-7K.

Although the general equalisation of the energy transformation uses a distributed technique through the modelling of the BG, it was easy to derive, optimise and explain the equations of state:

$$
\begin{gathered}
I=\frac{w d_{33} F_{m} \sin \left(2 n_{1} n_{2} \pi t\right)}{\sqrt{1+\left(w C_{p} R\right)^{2}}} \\
V=\frac{w d_{33} F_{m} \sin \left(2 n_{1} n_{2} \pi t\right)}{\sqrt{1+\left(w C_{p} R\right)^{2}}} R
\end{gathered}
$$

The resulting power output can be expressed as follows:

$$
P_{R M S}(t)=V . I=\left[\frac{w d_{33} F_{m} \sin \left(2 n_{1} n_{2} \pi t\right)}{\sqrt{1+\left(w C_{p} R\right)^{2}}}\right]^{2} \cdot R
$$

where, $\mathrm{F}_{\mathrm{m}}$ is a pressure force on the PZT-7K beams vertical to the pooling function of time $\mathrm{t}$, $\mathrm{w}$ presents the patch width, $\mathrm{n}_{1}$ is the natural frequency $(\mathrm{Hz})$ and $\mathrm{n}_{2}$ presents the beams quantity attached close to the suspension.

\subsection{Bond graph of suspension element combined with the transducer beams}

The established scheme is designed considering spring element, mass equivalent model and shock absorber scheme for each mode. The subsystem is constructed with several scheme degrees of liberty. This prototypical provides a great ride handling and provides the difference between the arbitrary input of the road surface. The perturbation input $\mathrm{w}$ presents the movement of the control output $\mathrm{z}$, as illustrated in Figure 1. The proposed BG of the conductor's seat suspension system affirm a global view of the system and its parameters optimisation. This model takes into account all the perturbations implemented in the conductor siege. The predicted electrical power amount is a function of the number of vibrations on an indifferent road. This new approach estimates an electrical power with a vehicle speed of $50 \mathrm{~km} / \mathrm{h}$. This improvement allows 
about 58W of needed energy recovery amount. In this section, a combination of the car wheel suspension attached to the harvester system model. The voltage output (in a series configuration) or the current signal output (in a parallel configuration) is amplified by the two electrically separated piezoelectric segments. The parallel assembly will duplicate the current single-element electrical energy harvesting as the piezoelectric efficiency capability. This latter has been chosen to increase the energy harvesting configuration by enhancing the output voltage respecting to a selected element arrangement. The random input function was applied to the hysteresis change course in the critical secondary loops of the piezoelectric harvester $(\mathrm{PH})$.

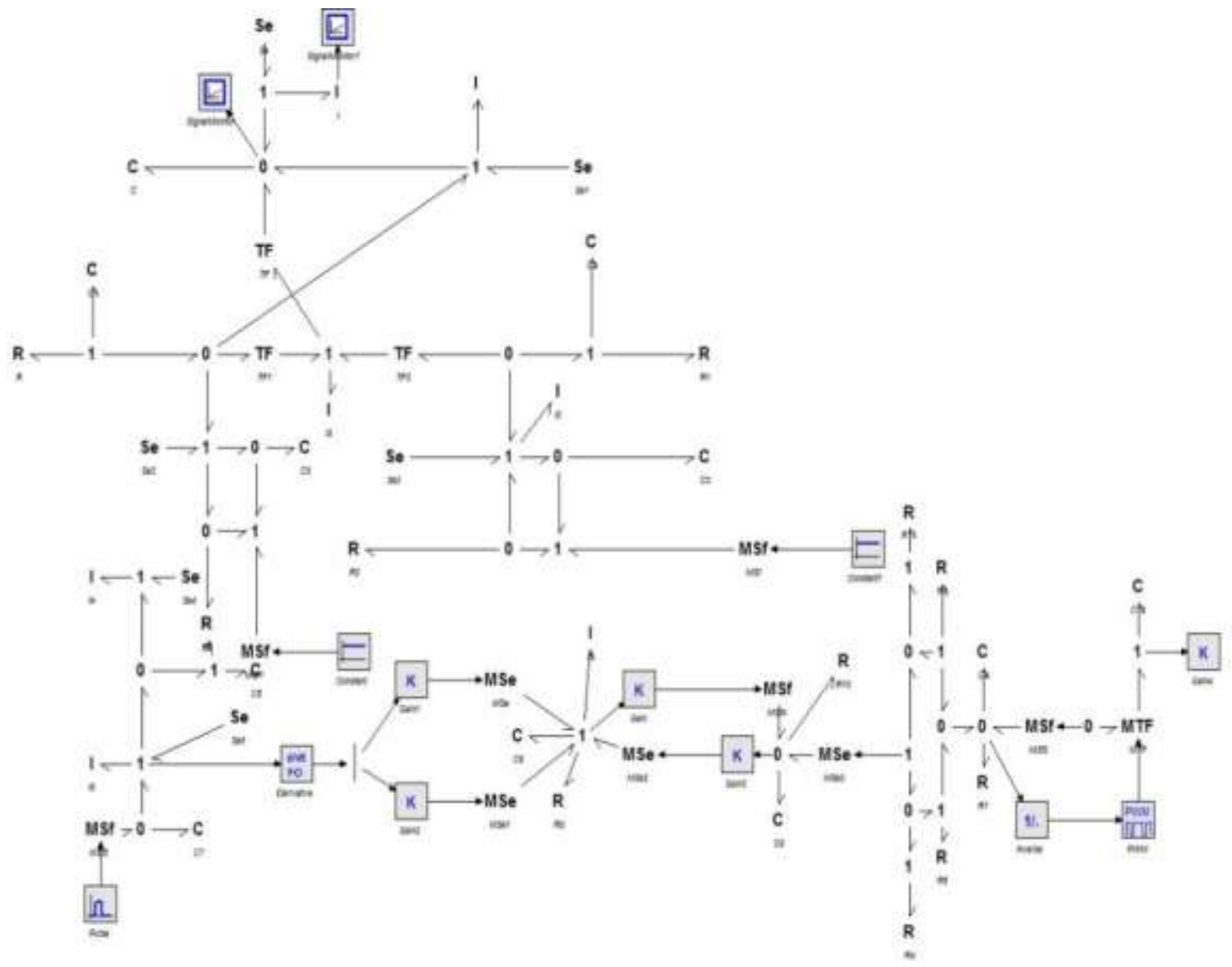

Figure 1. Bond graph model of piezoelectric harvester system under dynamic condition

In addition, piezoelectric technologies are more suitable than electromagnetic technologies for the application in MEMS, due to the limits of magnet miniaturization with current microfabrication processes as exposed :

From Junction 1, the state equations have been extracted as follow:

$$
\left\{\begin{array}{l}
e_{31}=e_{5}+e_{4} \\
f_{13}=f_{41}=f_{51}=F^{\prime}{ }_{m}-Z^{\prime} \\
e_{2}=e_{6}+e_{7}+e_{14} \\
f_{23}=f_{62}=f_{72}=Z^{\prime} \\
e_{8}=e_{9}+e_{10} \\
f_{8}=f_{9}=f_{10}=Z^{\prime}{ }_{2}-Z_{1}^{\prime}
\end{array}\right.
$$

From Junction 0, the equations of standard state have been excerpted as follow: 


$$
\left\{\begin{array}{l}
f_{1}=f_{2}+f_{3}=F^{\prime} \\
e_{1}=e_{2}=e_{31} \\
f_{7}=f_{8}+f_{11} \\
e_{7}=e_{8}=e_{11}
\end{array}\right.
$$

From Element I, the state equations have been extracted as follow:

$$
I_{11}: \mathrm{M}_{1}\left\{\begin{array}{l}
p^{\prime}{ }_{1}=e_{1} \\
f_{1}=\frac{1}{M_{2}} p_{1}=Z_{2}^{\prime}
\end{array} \text { and } I_{21}: \mathrm{M}_{2}\left\{\begin{array}{l}
p^{\prime}{ }_{21}=e_{21} \\
f_{21}=\frac{1}{M_{1}} p_{21}=Z_{1}^{\prime}
\end{array}\right.\right.
$$

From Element $\mathrm{C}$, the state equations have been extracted as follow:

$$
K_{21}:\left\{\begin{array}{l}
q^{\prime}{ }_{21}=f_{21} \\
e_{21}=K_{12} q_{21}
\end{array} \text { and } K_{12}:\left\{\begin{array}{l}
q_{9}^{\prime}=f_{9} \\
e_{9}=K_{1} q_{9}
\end{array}\right.\right.
$$

In (10) shows the linear characterised coefficients of patches:

$$
\left\{\begin{array}{l}
e\left(Z_{p z t}, t\right)=\left(R+R_{\text {Load }}\right) i(t)+L i^{\prime}(t) \\
e\left(Z_{p z t}, t\right)=r\left(Z_{p z t}, t\right) Z_{p z t}^{\prime} \\
P\left(Z_{p z t}, t\right)=V(t) . I(t)
\end{array}\right.
$$

This condition is maintained until the electrical power harvested assumes the highest level that is equivalent to the output potential. The equation is linearized for a specific value of the vehicle's velocity in impermanent calculations. In other words, both the current amount and the power rate from the sustained models of hysteresis have been carried out from the embedded piezoelectric transducers (EPT) frequency. The overall simplicity of the proposed alternative presented a benefit in the ratios of generation and internal power consumption.

\section{SIMULATION RESULTS AND DISCUSSION}

In this section, the numerical proof from simulation has been discussed for this complex dynamic piezoelectric harvester. The system exhibits a small amount of vibration lost that is converted to electric power when the model characteristics take a different level of values. Numerical measurements are performed in this section to demonstrate the productivity of the proposed transducer combined with the suspension system. The storage approach allows increasing the energy production and reducing the energy consumption.

The road factors involved in these demonstrations are very close to the characteristics of an actual automobile see Table 1 . The suspension parameters of the car seat have been adapted to the acceleration conditions of the driver's body. However, the vibration impact on the mass of the car has been reduced. The fast system modelling using BG estimate and verifies the implementation of the reduced model with physical reality. This approach is very attractive to harvest more electrical energy from the vibration. Hysteresis in a piezoelectric energy amplifier system (PZTEAs) is produced under conditions of relatively static operation that affect dynamic performance. However, the harvester hysteresis behaviour is analysed using mechanical finite element analysis software (ANSYS) as shown in Figure 2.

Table 1. Road classes according to ISO 8608

\begin{tabular}{ccc}
\hline Variable & Speed $(\mathrm{km} / \mathrm{s})$ & Power $(\mathrm{mW})$ \\
\hline $\mathrm{A}$ & $70-130$ & 8.6 \\
$\mathrm{~B}$ & $50-90$ & 12.4 \\
$\mathrm{C}$ & $30-60$ & 15.3 \\
\hline
\end{tabular}




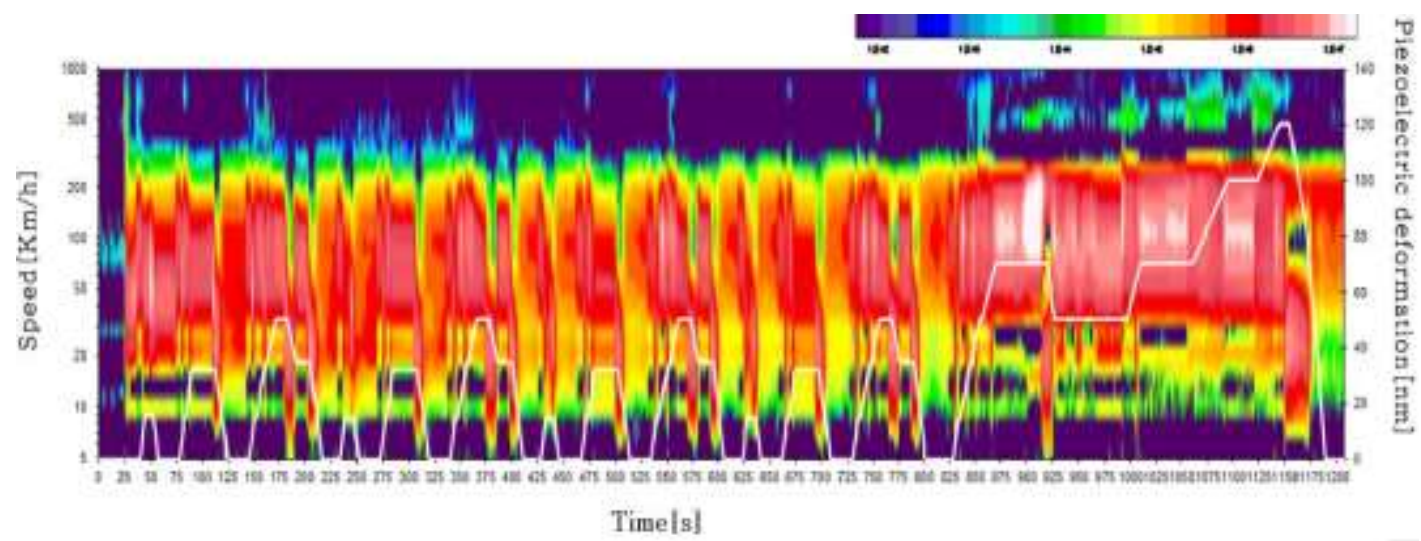

Figure 2. Expansion of piezoelectric harvester under signal loops

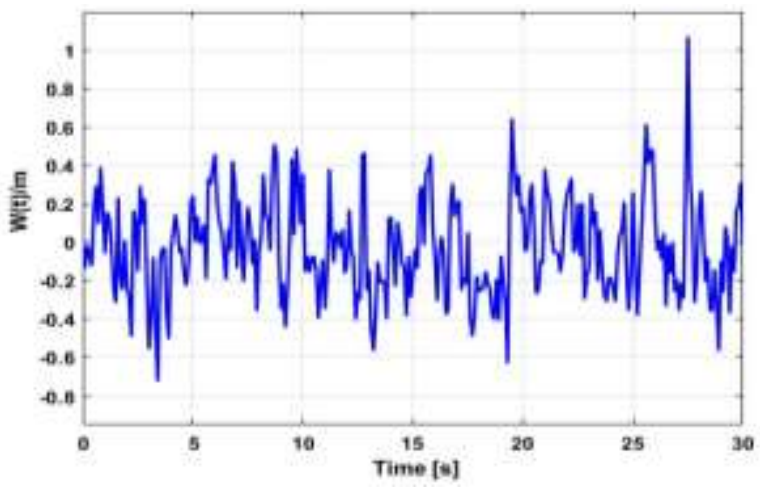

(a)

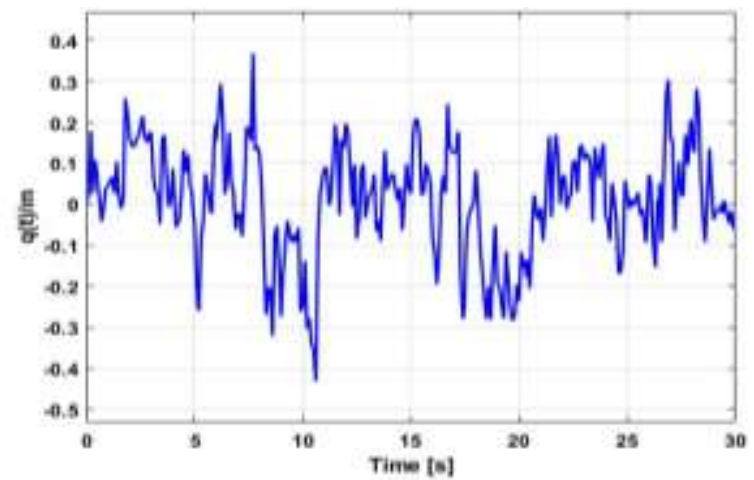

(b)

Figure 3. Effects of real source; (a), and ideal source (b) of flow

The identification of the reciprocal model and its corresponding matrix is ensured by the bond graph inverse (BGI). The final power value is specified according to adjusted natural frequencies from vibration acceleration $[1 \mathrm{~Hz}, 90 \mathrm{~Hz}]$. In those conditions, the transducer feedback to energetic forces is controlled and simulation of potentially life-threatening accelerations is required. The scavenger energy value is a function of vehicle speed in the range of $30 \mathrm{~m} / \mathrm{s}$ to $85 \mathrm{~m} / \mathrm{s}$ on road profile respectively B, C and D as present Figures 3 (a) and 3 (b). The amount of electrical energy is predicted by the square root of the vehicle speed as well as by the fact that the transverse displacement and speeds of the vehicle are important. These simulations demonstrate the effectiveness of this approach in harvesting electrical energy. In addition, the increase in vehicle acceleration provides an indication an important EE. The electrical energy has been generated on the road surface due to the fact that the relative displacements and speeds of the suspended and unsuspended body are all proportional.

The vehicle seat powered all devices by the harvestable energy value as given in Figure 4 . Figures 4 (c) and 4 (d) illustrate that the amount of electrical power expands between $308 \mathrm{~mW}$ and $500 \mathrm{~mW}$, respectively, surrounding $1 \mathrm{~h}$ of car movement at $60 \mathrm{~km} / \mathrm{h}$, from $0.9 \mathrm{~W}$ to $15 \mathrm{~W}$ and from $10 \mathrm{~W}$ to $80 \mathrm{~W}$, after the vehicle speed rises from $50 \mathrm{~km} / \mathrm{h}$ to $100 \mathrm{~km} / \mathrm{h}$. In this document, the simulation results were founded for an adequate set frequency value of $90 \mathrm{~Hz}$. The amplitudes of the suspended mass accelerations increase significantly which affect the power output amount. The mow electrical power determination from the passenger (conductor) siege suspension is achieved by examining exact natural frequency range. This system has the same physical geometry and material characteristics as the results of the previous modelling simulations.

Figure 4 (c) shows that the electrical tension grows linearly with the increase of the vehicle load and velocity. Therefore, under these conditions, it is confirmed that the amount of external vibration increases the voltage density level and consequently the collected energy is highly significant. The transducer harvester adopted in suspension system allows the necessary energy recovery for the appropriate dimensions. In addition, the fabrication and realisation of such a system is necessary to note that the defined the energy 
requirement to be consumed by the sensors. From the equations given by the BG modelling the appropriate dimensions of the armature has been achieved. The piezoelectric factors are resilient for a trivial length and large thickness and viscosity. The dimensions of the piezoelectric devices proposed in this paper improved the characteristics of the suspensions (stiffness and dampers).

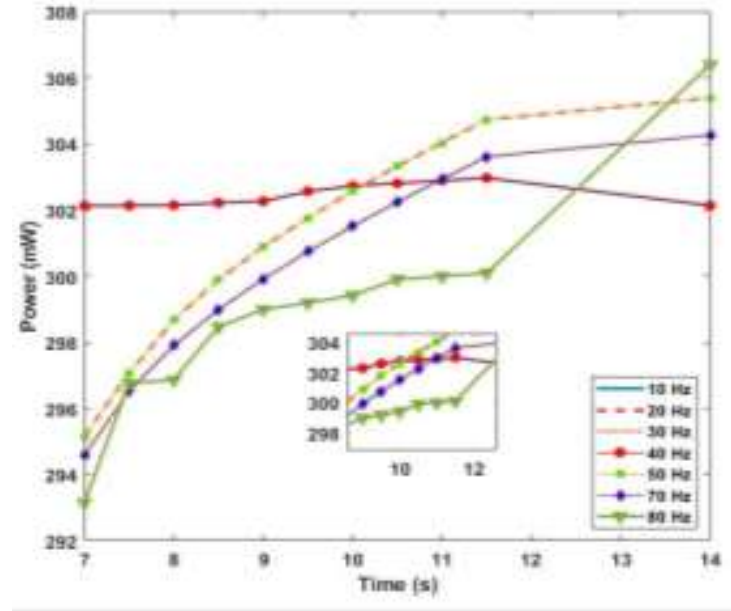

(a)

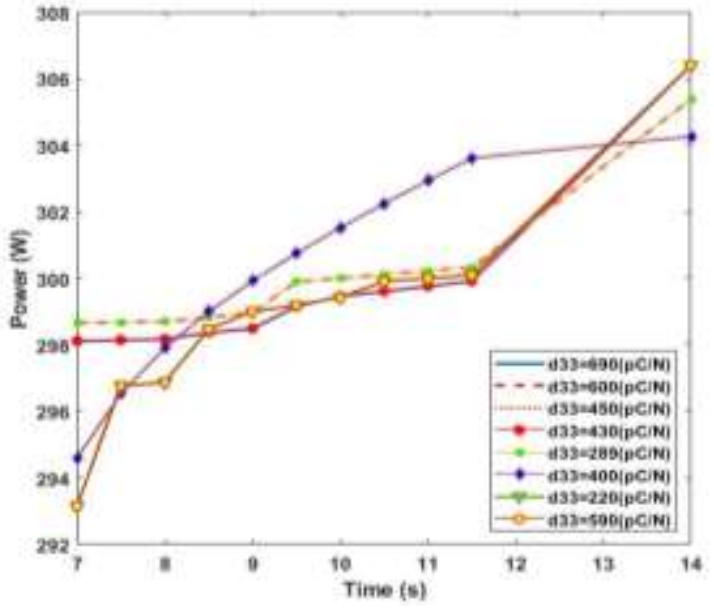

(c)

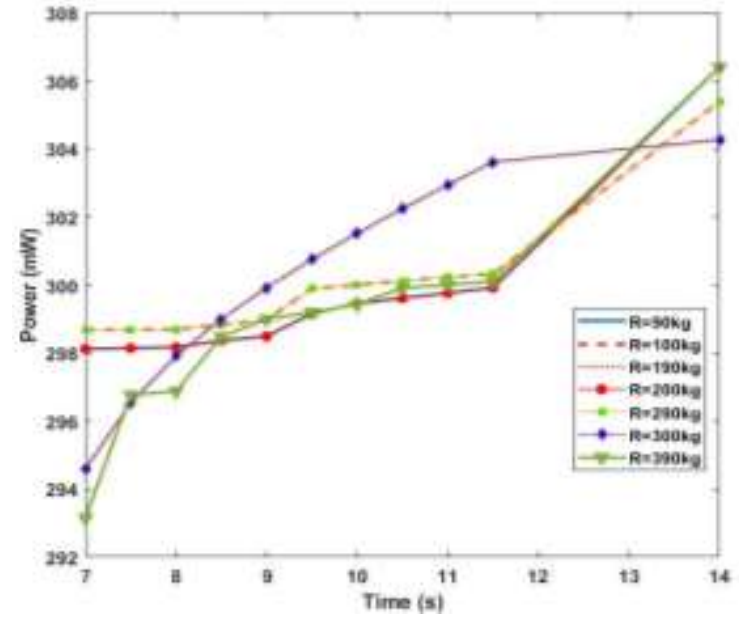

(b)

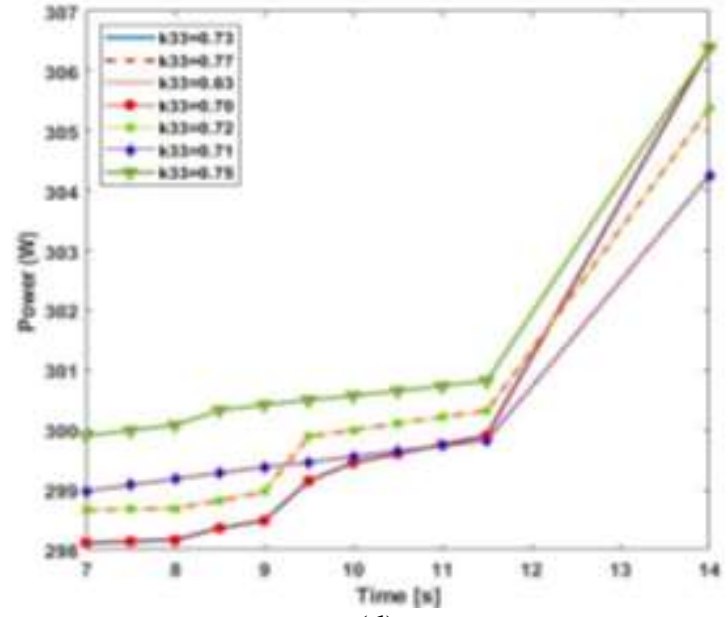

(d)

Figure 4. Classification of energy harvesting amount under piezoelectric dynamic condition; (a) major resonance frequency, an external load resistance (b), (c) piezoelectric constant and

(d) Mass density of the PZT-k

\section{CONCLUSION}

This paper aims to develop a piezoelectric harvester system mounted on seat suspension to collect and convert the small vibration energy amount into electrical energy. This model improved the power supply needed for the EV by the piezoelectric component in the resonant frequency of this disturbance. In addition, the electrical energy output appeared from the car's load is included in the proposed complete Bond Graph model. The simulation results showed that the electrical power supply was sufficient for the EV needs. The harvested electrical energy quantity increased from $300 \mathrm{~mW}$ to $599 \mathrm{~mW}$, from $0.4 \mathrm{~W}$ to $14 \mathrm{~W}$ and from $1 \mathrm{~W}$ to $100 \mathrm{~W}$ respectively under road travelling (levels $\mathrm{A}, \mathrm{B}$ and $\mathrm{C}$ ). Overall, the piezoelectric harvester is preliminarily chosen the simulation results are encouraging. The next phase of our research will therefore focus on the different experimental conditions, including higher road roughness excitations. As future work, structural conception and factors optimization of this harvester system and validation test in the real EV are planned. 


\section{REFERENCES}

[1] A. Gonçalves, A. Almeida, E. de Moura, C. da R. Souto, and A. Ries, "Active vibration control in a two degrees of freedom structure using piezoelectric transducers associated with negative capacitance shunt circuits," Int. J. Dyn. Control, Jun. 2020, doi: 10.1007/s40435-020-00652-9.

[2] T. Yang, Q. Cao, and Z. Hao, "A novel nonlinear mechanical oscillator and its application in vibration isolation and energy harvesting," Mech. Syst. Signal Process., vol. 155, p. 107636, Jun. 2021, doi: 10.1016/j.ymssp.2021.107636.

[3] Z. Wu, G. Xu, H. Yang, and M. Li, "Analysis of Damping Characteristics of a Hydraulic Shock Absorber," Shock Vib., vol. 2021, pp. 1-10, Feb. 2021, doi: 10.1155/2021/8883024.

[4] H. A. Marzog, M. Jaleel Mohsin, and M. Azher Therib, "Chaotic systems with pseudorandom number generate to protect the transmitted data of wireless network," Indones. J. Electr. Eng. Comput. Sci., vol. 21, no. 3, p. 1602, Mar. 2021, doi: 10.11591/ijeecs.v21.i3.pp1602-1610.

[5] S. Touairi and M. Mabrouki, "Control and modelling evaluation of a piezoelectric harvester system," Int. J. Dyn. Control, Mar. 2021, doi: 10.1007/s40435-021-00764-w.

[6] S. Suherman, F. Fahmi, U. Hasnita, and Z. Herri, "Design and characteristics assessment of wireless vibration sensor for buildings and houses," Indones. J. Electr. Eng. Comput. Sci., vol. 21, no. 3, p. 1381, Mar. 2021, doi: 10.11591/ijeecs.v21.i3.pp1381-1388.

[7] S. Li, J. Xu, X. Pu, T. Tao, H. Gao, and X. Mei, "Energy-harvesting variable/constant damping suspension system with motor based electromagnetic damper," Energy, vol. 189, p. 116199, Dec. 2019, doi: 10.1016/j.energy.2019.116199.

[8] Y. K. Jelbaoui, E. M. Lamiaà, and A. Saad, "Fault diagnosis of a squirrel cage induction motor fed by an inverter using lissajous curve of an auxiliary winding voltage," Indones. J. Electr. Eng. Comput. Sci., vol. 21, no. 3, p. 1299, Mar. 2021, doi: 10.11591/ijeecs.v21.i3.pp1299-1308.

[9] A. AL-Shimmary, S. Kareem Radhi, and A. Kassim Hussain, "Haar wavelet method for solving coupled system of fractional order partial differential equations," Indones. J. Electr. Eng. Comput. Sci., vol. 21, no. 3, p. 1444, Mar. 2021, doi: 10.11591/ijeecs.v21.i3.pp1444-1454.

[10] I. Bessadet, H. Tédjini, and I. Khalil Bousserhane, "Hydrogen electrified railways based shunt hybrid filter," Indones. J. Electr. Eng. Comput. Sci., vol. 21, no. 3, p. 1291, Mar. 2021, doi: 10.11591/ijeecs.v21.i3.pp1291-1298.

[11] D. Zhao et al., "Hydrokinetic piezoelectric energy harvesting by wake induced vibration," Energy, vol. 220, Apr. 2021, doi: 10.1016/j.energy.2020.119722.

[12] B. Lafarge, S. Grondel, C. Delebarre, O. Curea, and C. Richard, "Linear electromagnetic energy harvester system embedded on a vehicle suspension: From modeling to performance analysis," Energy, vol. 225, p. 119991, Jun. 2021, doi: 10.1016/j.energy.2021.119991.

[13] S. Touairi, Y. Khouya, C. Bahanni, Z. Khaouch, and M. Mabrouki, "Mechatronic Control and Modeling of a Piezoelectric Actuator," in 2019 International Conference on Wireless Technologies, Embedded and Intelligent Systems (WITS), Fez, Morocco, Apr. 2019, pp. 1-6, doi: 10.1109/WITS.2019.8723668.

[14] S. Touairi and M. Mabrouki, "Mechatronic modeling and control of energy recovery in motorcycle tires," in 2020 IEEE 6th International Conference on Optimization and Applications (ICOA), Beni Mellal, Morocco, Apr. 2020, pp. 1-5, doi: 10.1109/ICOA49421.2020.9094495.

[15] A. M. Alsabari, M. K. Hassan, A. Cs, and R. Zafira, "Modeling and validation of lithium-ion battery with initial state of charge estimation," Indones. J. Electr. Eng. Comput. Sci., vol. 21, no. 3, p. 1317, Mar. 2021, doi: 10.11591/ijeecs.v21.i3.pp1317-1331.

[16] A. Pasharavesh, R. Moheimani, and H. Dalir, "Nonlinear energy harvesting from vibratory disc-shaped piezoelectric laminates," Theor. Appl. Mech. Lett., vol. 10, no. 4, pp. 253-261, Apr. 2020, doi: 10.1016/j.taml.2020.01.032.

[17] S. Touairi and M. Mabrouki, "Optimization of Car's Electric Power Consumption Using Piezoelectric System," Int. J. Control Autom., vol. 12, no. 10, pp. 23-32, Oct. 2019, doi: 10.33832/ijca.2019.12.10.03.

[18] S. Touairi and M. Mabrouki, "Optimization of Energy Harvesting System design by Functional Analysis," in 2020 1st International Conference on Innovative Research in Applied Science, Engineering and Technology (IRASET), Meknes, Morocco, Apr. 2020, pp. 1-6, doi: 10.1109/IRASET48871.2020.9092253.

[19] S. Touairi and M. Mabrouki, "Optimization of Harvester System in embedded vehicle systems via Bond Graph modeling algorithm," in 2020 IEEE 6th International Conference on Optimization and Applications (ICOA), Beni Mellal, Morocco, Apr. 2020, pp. 1-6, doi: 10.1109/ICOA49421.2020.9094463.

[20] A. Pasharavesh, R. Moheimani, and H. Dalir, "Performance Analysis of an Electromagnetically Coupled Piezoelectric Energy Scavenger," Energies, vol. 13, no. 4, p. 845, Feb. 2020, doi: 10.3390/en13040845.

[21] A. Senta and L. Šerić, "Remote sensing data driven bathing water quality assessment using sentinel-3," Indones. J. Electr. Eng. Comput. Sci., vol. 21, no. 3, p. 1634, Mar. 2021, doi: 10.11591/ijeecs.v21.i3.pp1634-1647.

[22] H. Abed Alwally Abed Allah and R. Abduladheem Hasan, "Secure and smart system for monitoring patients with critical cases," Indones. J. Electr. Eng. Comput. Sci., vol. 21, no. 3, p. 1800, Mar. 2021, doi: 10.11591/ijeecs.v21.i3.pp1800-1807.

[23] S. Touairi, Y. Khouya, C. Bahanni, and M. Mabrouki, "Sliding-Mode Control of Piezoelectric Actuator using Bond Graph," in 2019 5th International Conference on Optimization and Applications (ICOA), Kenitra, Morocco, Apr. 2019, pp. 1-7, doi: 10.1109/ICOA.2019.8727686.

[24] S. Budiyanto, F. A. Silaban, L. Silalahi, and T. Pangaribowo, "The automatic and manual railroad door systems based on IoT," Indones. J. Electr. Eng. Comput. Sci., vol. 21, no. 3, p. 1847, Mar. 2021, doi: 10.11591/ijeecs.v21.i3.pp1847-1855. 
[25] M. Liu, W.-C. Tai, and L. Zuo, "Vibration energy-harvesting using inerter-based two-degrees-of-freedom system," Mech. Syst. Signal Process., vol. 146, p. 107000, Jan. 2021, doi: 10.1016/j.ymssp.2020.107000.

[26] S. Oberst, B. Halkon, J. Ji, and T. Brown, Eds., Vibration Engineering for a Sustainable Future: Active and Passive Noise and Vibration Control, Vol. 1. Cham: Springer International Publishing, 2021.

[27] S. Touairi, A. Bouzid, and M. Mabrouki, "Road handling of regenerative motorcycle suspensions and energy harvesting," Khouribga, Morocco, 2021, p. 020017. doi: 10.1063/5.0049387.

[28] S. Touairi and M. Mabrouki, "Improve the Energy Harvesting Alternatives Using the Bond Graph Approach for Powering Critical Autonomous Devices," In book: Digital Technologies and Applications. Fes, Morocco, 2021. doi: 10.1007/978-3-030-73882-2_143.

\section{BIOGRAPHIES OF AUTHORS}

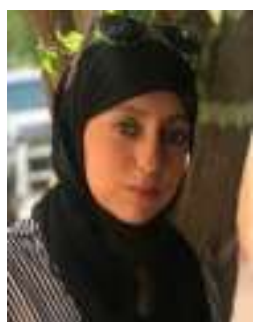

Souad Touairi received the S.M degree in mechatronic engineering from the Abdelmalek Essadi University, Morocco, in 2016, department of Mechanical Engineering. Her research interests include robotics, energy harvesting, and control. She is currently a Ph.D. student in the fields of mechatronics, robotics, and renewable energy in Faculty of Sciences and Techniques, University Sultan Moulay Slimane Beni Mellal, and researcher in the field of harvested energy engineering. President of USMS-Young Minds Section of the European Physics Society. My current projects are 1-AFM and STM projects 2-Harvesting energy project 3-Solar Decathlon Africa2019 competition.

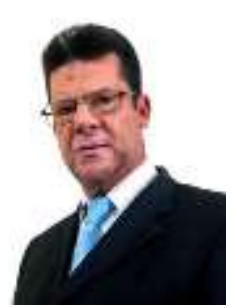

Mustapha Mabrouki currently works at the Physics Department (Full professor), University Sultan Moulay Slimane, Faculty of Sciences and Techniques, Beni Mellal, Morocco. Mustapha does research in Smart grids and smart cities (optimization models for balancing energy), Photovoltaic Materials Synthesis and Integration, Phosphates and derivatives, Biotechnology and Microbiology. My current projects are 1- 'PROPRE.MA'. Build photovoltaic yield maps of grid connected mono, poly and amorphous PV modules for all Morocco with land calibration on 20 identical plants. 2-AFM project 3-Phosphate project 4-Solar Decathlon Africa2019 competition. 